Citation: Beal. C, Stewart, RA., Spinks, A., Fielding, K. (2011) Using smart meters to identify social and technological impacts on residential water consumption, Water Science and Technology:Water Supply, doi:10.2166/ws.2011.088.

\title{
USING SMART METERS TO IDENTIFY SOCIAL AND TECHNOLOGICAL IMPACTS ON RESIDENTIAL WATER CONSUMPTION
}

Cara Beal $^{1}$, Rodney A. Stewart ${ }^{2}$, Anneliese Spinks ${ }^{3}$, Kelly Fielding ${ }^{4}$

1. Research Fellow, Griffith School of Engineering, Griffith University,

2. Director, Centre for Infrastructure Engineering \& Management, Griffith University,

3. Project Scientist, CSIRO,

4.Senior Research Fellow, Institute for Social Science Research, University of

Queensland,

Keywords:, smart meters, residential water consumption intentions, trace analysis

\begin{abstract}
Studies have shown that householders' perceptions of their water use are often not well matched with their actual water use. There has been less research, however, investigating whether this bias is related to specific types of end use and/or specific types of socio-demographic and socio-demographic household profiles. A high resolution smart metering study producing a detailed end use event registry as well as psycho-social and socio-demographic surveys stock inventory audits and selfreported water diaries was completed for 250 households located in South-east Queensland, Australia. The study examined the contributions of end uses to total water use for each group identified as "low", "medium" or "high" water users. Analyses were conducted to examine the socio-demographics variables such as income, percentage of water efficient stock, family size and composition that characterise each self-identified water usage group. The paper concludes with a discussion of the general characteristics of groups that overestimate and underestimate their water use and how this knowledge can be used to inform demand management policy such as targeted community education programmes.
\end{abstract}

\section{INTRODUCTION}

Water consumption has been shown to be influenced by some key sociodemographic factors: household income, household occupancy and house size (Renwick and Archibald 1998, Kim et al. 2007, Turner et al. 2009). Despite a growing awareness in water conservation amongst the public in the last decade or so, studies have shown that householders' perceptions of their water use are often not well matched with their actual water use (Hamilton 1985, Millock and Nuages 2010). There is less known, however, on whether this bias is related to specific end uses and/or socio-demographic household profiles (Fielding et al. 2009). Hamilton (1985) observed that self-reported water consumption was not an accurate method of determining residential water use. The disparity between believed and actual water use was shown to be influenced by socio-economic status and conservation 
behaviours, where people from a higher incomes and people who were 'conservation aware' tended to more accurately estimate their water use (Hamilton 1985).

Wutich (2009) observed that a water diary was more effective in capturing water consumption and water end uses than prompted or free recall. In this instance, selfreported water use, via diary records has been shown to be an accurate and reliable approach.

The aim of this study was to compare actual versus believed water consumption across a sample of households in South East Queensland (SEQ). A further aim was to explore the general characteristics (household water end use, income, family size etc.) of groups that overestimate and underestimate their water use and how this knowledge can be used to inform demand management policy such as targeted community education programmes. Data for this paper was generated from the SEQ Residential End Use Study (SEQREUS) which is a larger research project funded from the Urban Water Security Research Alliance.

\section{METHODS}

A water fixture/appliance stock survey on the study sample was conducted in order to qualify how householders interact with such stock. In addition to the stock survey, each household was asked to complete a water diary where as many internal and external water use events as possible were recorded over a 7 day period. Knowledge on household occupancy and family characteristics was extracted from the aligned Systematic Social Analysis (SSA) project household survey (Spinks et al. 2010). The aim of the survey was to capture attitudes and behaviours toward household water conservation. In the last stage of the survey, respondents were asked directly about their household water consumption. Firstly, respondents were asked to write down their average daily water use (litres per household) provided in their latest household rates notice. Immediately following this the respondents were asked "Do you believe you are a high, medium or low water user?", with an option for "Don't know". Information from this database was used to cluster the four selfreported water user groups: "low", "medium", "high" or "don't know". Total water use for each group was then examined on the basis of specific end uses, sociodemographics, water fixture/appliance stock. Two-tailed, independent $t$-Tests and other descriptive statistics were performed on the data using Microsoft Excel and SPSS $^{\circledR}$ software packages.

The study areas were located in the south east corner of Queensland (Figure 1). A sub-sample for the SEQREUS project was generated from a larger study which involved the completion of a questionnaire of over 1,500 homes across SEQ. The relationship between smart metering equipment, household stock inventory surveys and flow trace analysis is shown in Figure 2. A detailed discussion on the research methods is provided in Beal et al. (2011). Briefly, existing standard water meters were replaced with high resolution meters that were capable of providing 0.014 L/pulse outputs in 5 second intervals to wireless data loggers. A continuous, twoweek sample of measured consumption data was disaggregated into end use events (e.g. toilet, shower, clothes washer, taps) using the Trace Wizard ${ }^{\mathrm{TM}}$ software (Aquacraft 2010). Individual end uses were identified using a combination of flow trace patterns shown in the software and information from the water audits and 
diaries (e.g. type and water usage of washing machine, shower and tap flow rates, presence of dishwasher etc.).

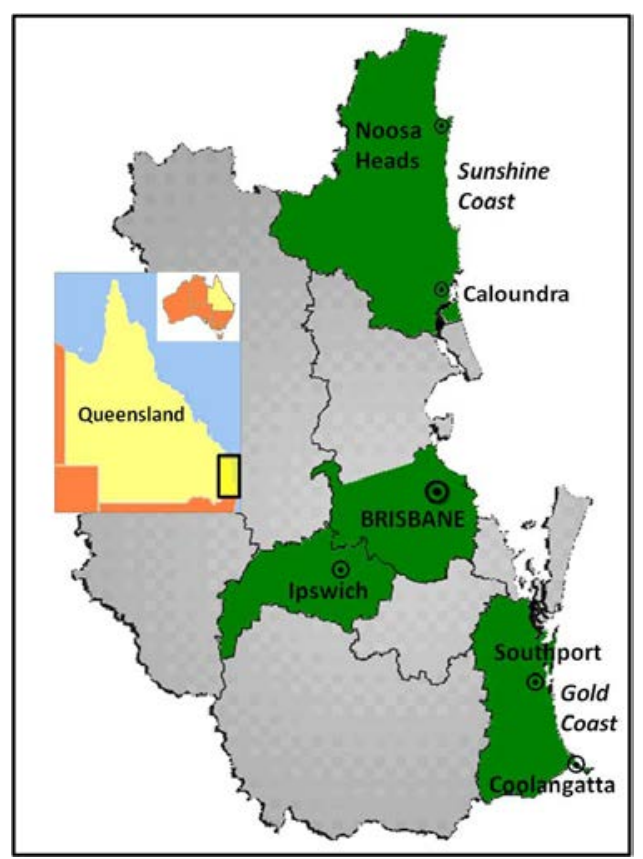

Figure 1. Regions examined in SEQEUS.

Inset: location of SEQ in Australia.

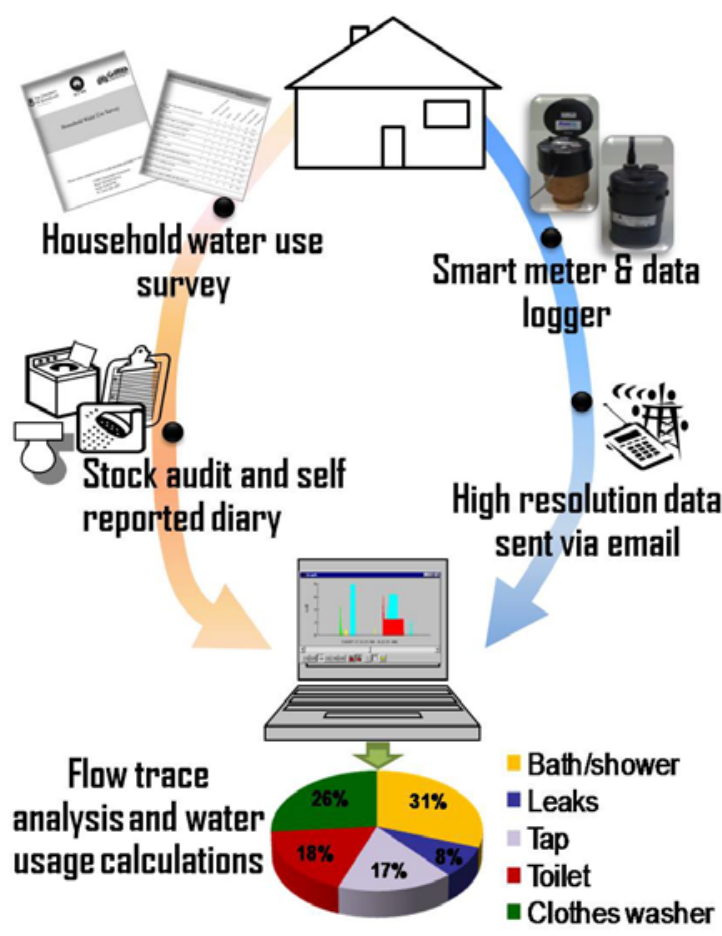

Figure 2. Schematic flow of process for acquisition, capture, transfer and analysis of water flow data.

\section{RESULTS AND DISCUSSION}




\section{End use patterns and socio-demographics}

The relationship between income categories, people per household and total water usage on a per capita basis is demonstrated in Figure 3. Previous studies such as Kim et al. (2007) and Kenney et al. (2008) have reported a higher water consumption per capita for higher-income homes with greater occupancies, although this was not observed in this study. Data in Figure 3 shows a trend for higher income families to have higher household occupancies but use relatively less water consumption than lower-income, smaller sized families. This may reflect the likelihood of the occupants of a higher income household to be away from home for greater periods, when compared to low income groups such as single parent families and pensioners. Willis et al. (2009) found no significant differences between water consumption across four different socio-economic groups although the higher-income group used the least volume of water during the period of analysis. Willis et al. (2009) suggested that the higher socio-economic households would be more likely to purchase water efficient appliances such as washing machines and dishwashers. This trend is also explored later in this paper.'

The average age is shown in black circles on the bar plots of each income category in Figure 3. There is a noticeable trend for older households to use more water. Willis et al. (2009) has reported that retired couples tend to use more water per capita and this may be due to medical requirements, increased toilet flushing, and increased presence in the home throughout the day. Conversely, younger households were observed to use less water per capita (litres per person per day [ L/p/d]) despite the households being typically larger. This coincided with higher household incomes also where the factors of higher efficiency appliances, potentially greater conservation awareness, and less time in the home may also be at play.

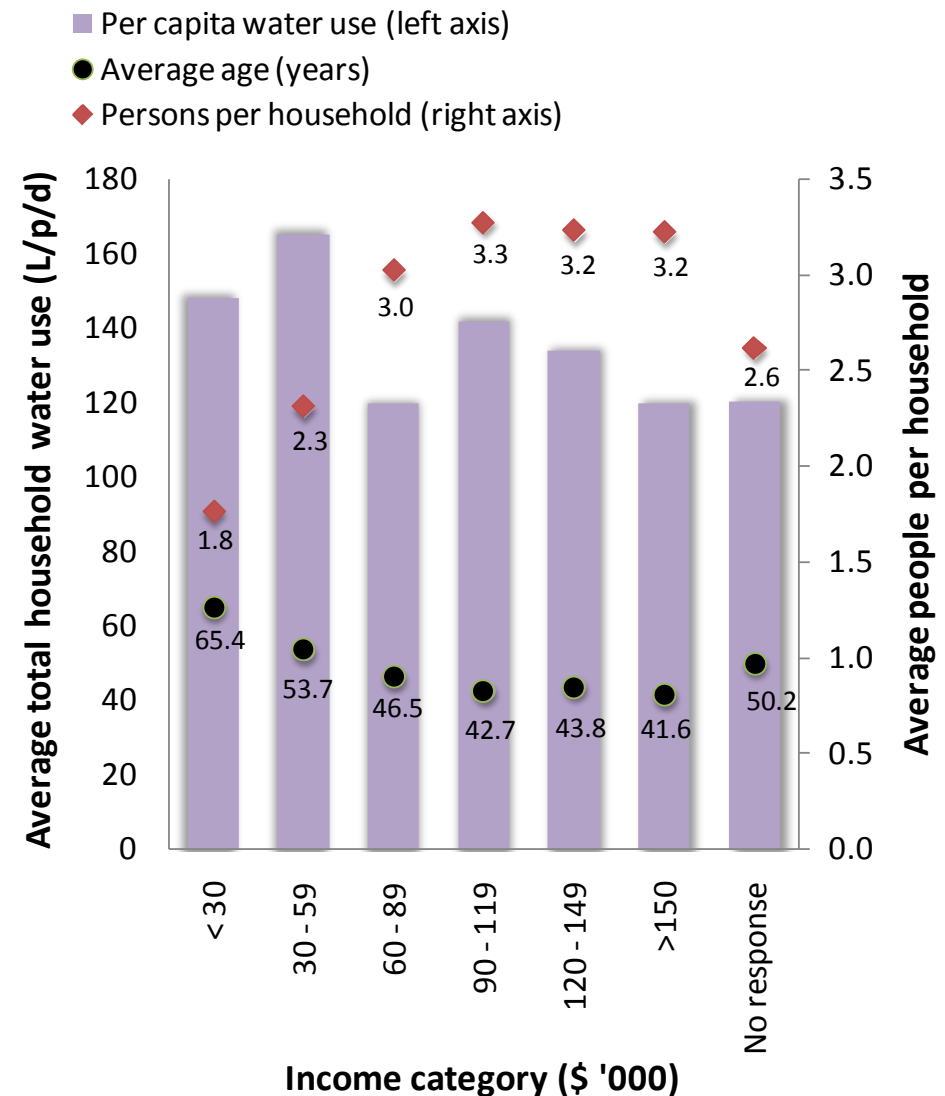


Figure 3 Relationship between income category and average household occupancy

\section{Actual versus perceived water use behaviours}

The responses of participants of the aforementioned SSA survey have been matched with the actual water use recorded (Figure 4). A summary of descriptive statistics is provided in Table 1 . Interestingly, from a total of 222 respondents, only a small number of households ( $n=21$ or $9.5 \%$ ) identified as being 'low' water users although their actual water use was $142 \mathrm{~L} / \mathrm{p} / \mathrm{d}$ which was just under the average for the entire region. Following on from this, people who identified as 'medium' water users ( $n=90$ or $40.5 \%$ ) actually used more than the study average of $155 \mathrm{~L} / \mathrm{p} / \mathrm{d}$ and people who identified as 'high' water users ( $n=94$ or $42 \%)$ used the least at $130 \mathrm{~L} / \mathrm{p} / \mathrm{d}$ (Figure 4a).

The trend continued when analysing on a per household basis where the difference between 'high' and 'medium' water consumption was statistically different $(p<0.05)$ at 469 litres per household per day (L/hh/d) compared with $298 \mathrm{~L} / \mathrm{hh} / \mathrm{d}$, respectively (Figure 5a). The remaining respondents who answered 'don't know' ( $n=17$ or $8 \%$ ) had an average water use of $132 \mathrm{~L} / \mathrm{p} / \mathrm{d}$. One implication of this is that water demand management policy cannot rely solely on individual household attitudes and beliefs to reduce water consumption. Mandatory measures such as water restrictions or incentives such as rainwater tank rebates are possibly more reliable in reducing residential demand, as has been shown in the past (Kenney et al. 2008, Renwick and Archibald, 1998).

Table 1. Summary of descriptive statistics for each self reported water use group

\begin{tabular}{|c|c|c|c|c|c|c|c|c|}
\hline \multirow{2}{*}{ Statistic } & \multicolumn{2}{|c|}{ "High" } & \multicolumn{2}{|c|}{ "Medium" } & \multicolumn{2}{|c|}{ "Low" } & \multicolumn{2}{|c|}{ "Don't know" } \\
\hline & $\mathrm{L} / \mathrm{p} / \mathrm{d}$ & $\mathrm{L} / \mathrm{hh} / \mathrm{d}$ & $\mathrm{L} / \mathrm{p} / \mathrm{d}$ & $\mathrm{L} / \mathrm{hh} / \mathrm{d}$ & $L / p / d$ & $\mathrm{~L} / \mathrm{hh} / \mathrm{d}$ & $L / p / d$ & $\mathrm{~L} / \mathrm{hh} / \mathrm{d}$ \\
\hline Mean & 130 & 295 & 155 & 465 & 142 & 385 & 132 & 333 \\
\hline $\begin{array}{c}\text { First } \\
\text { quartile }\end{array}$ & 92 & 174 & 98 & 279 & 104 & 219 & 80 & 124 \\
\hline Median & 114 & 245 & 134 & 384 & 132 & 315 & 116 & 262 \\
\hline $\begin{array}{l}\text { Third } \\
\text { quartile }\end{array}$ & 152 & 368 & 178 & 528 & 160 & 494 & 148 & 391 \\
\hline
\end{tabular}

The key end uses that were associated with the increased water use for 'medium' and 'low' water users were shower, clothes washer and toilet (Figures $4 \mathrm{~b}$ and $5 \mathrm{~b}$ ). Leakage rates were the greatest for the respondents who 'didn't know' suggesting that they may have been aware of a leak but not sure its contribution to their total household water consumption. 


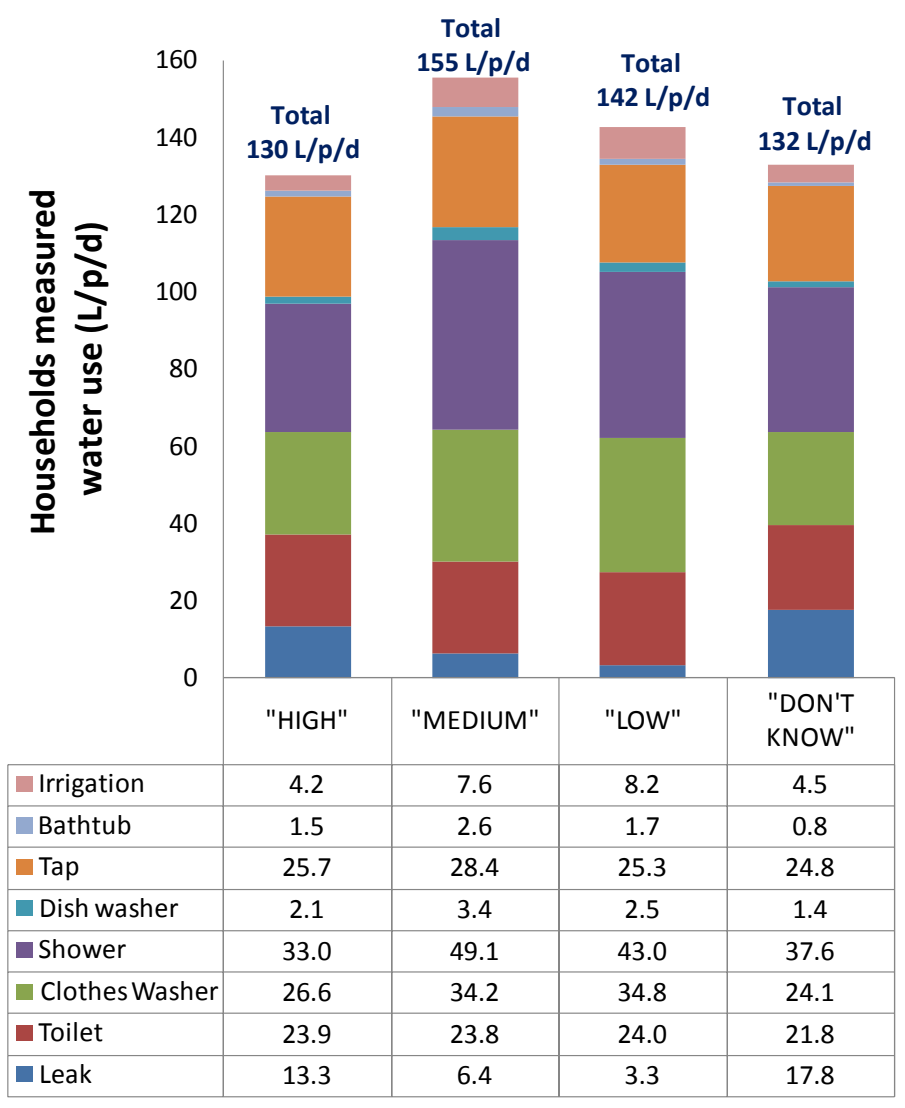

(a) Per capita daily consumption (L/p/d)

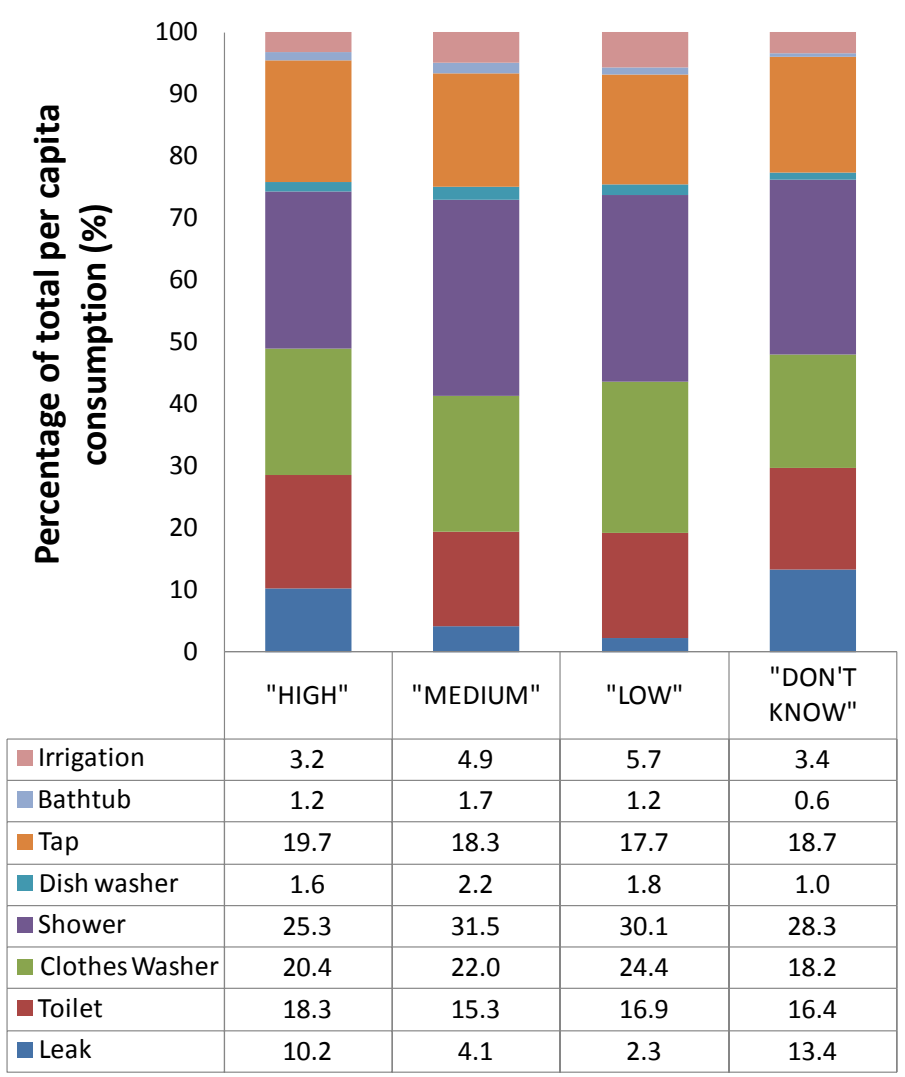

(b) Percentage of total per capita consumption (\%) 
Figure 4 Comparisons of actual per capita water use with self-identified users

In terms of household size and composition, there was some evidence to suggest that people with larger families (higher household occupancies) underestimated their total water use (Figure 6a). A significantly lower $(p<0.05)$ household occupancy for 'high' water users compared to 'medium' users was detected (Figure 6a). Additionally, there were also significant differences $(p<0.05)$ between the number of children in households that identified as 'high' users and the 'medium' and 'low' users (Figure 6b). Therefore, people with larger families may tend towards underestimating the contribution of children in household water demand. There may be a lack of knowledge of how and when children are using the household water.

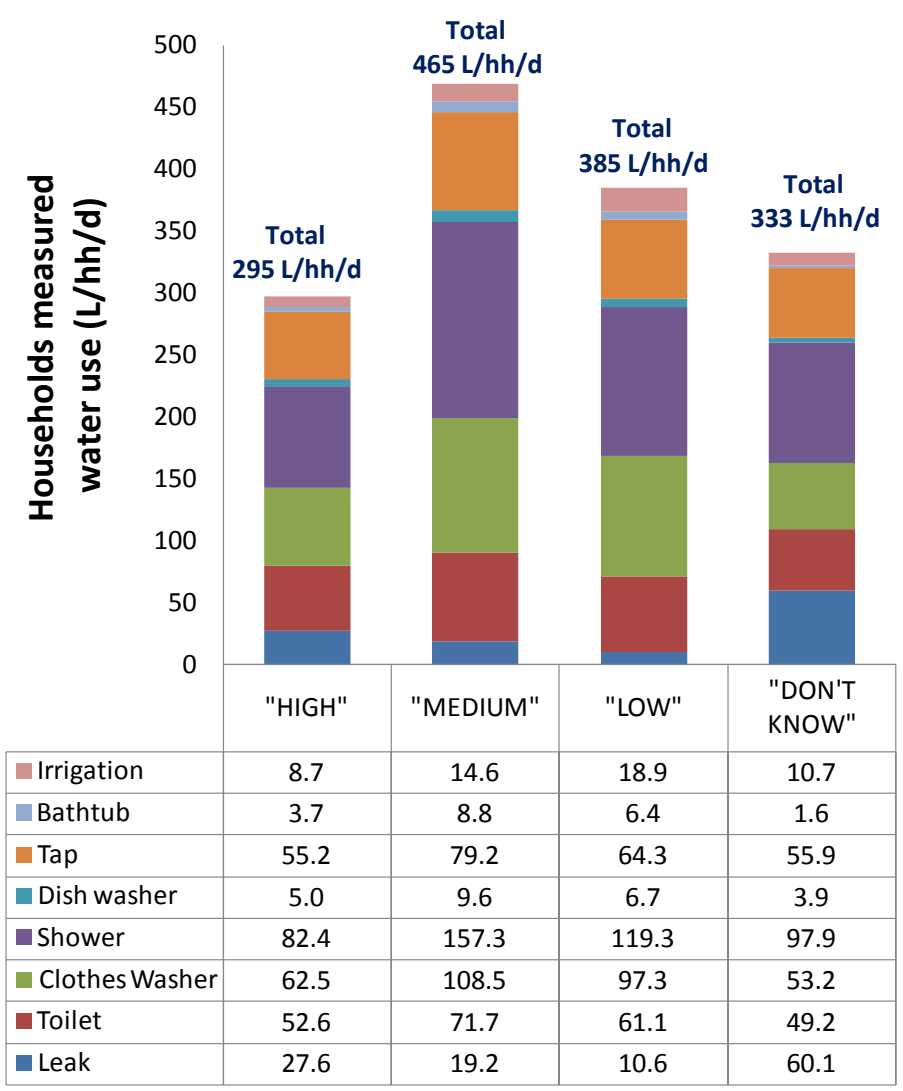

(a) Per household daily consumption (L/hh/d) 


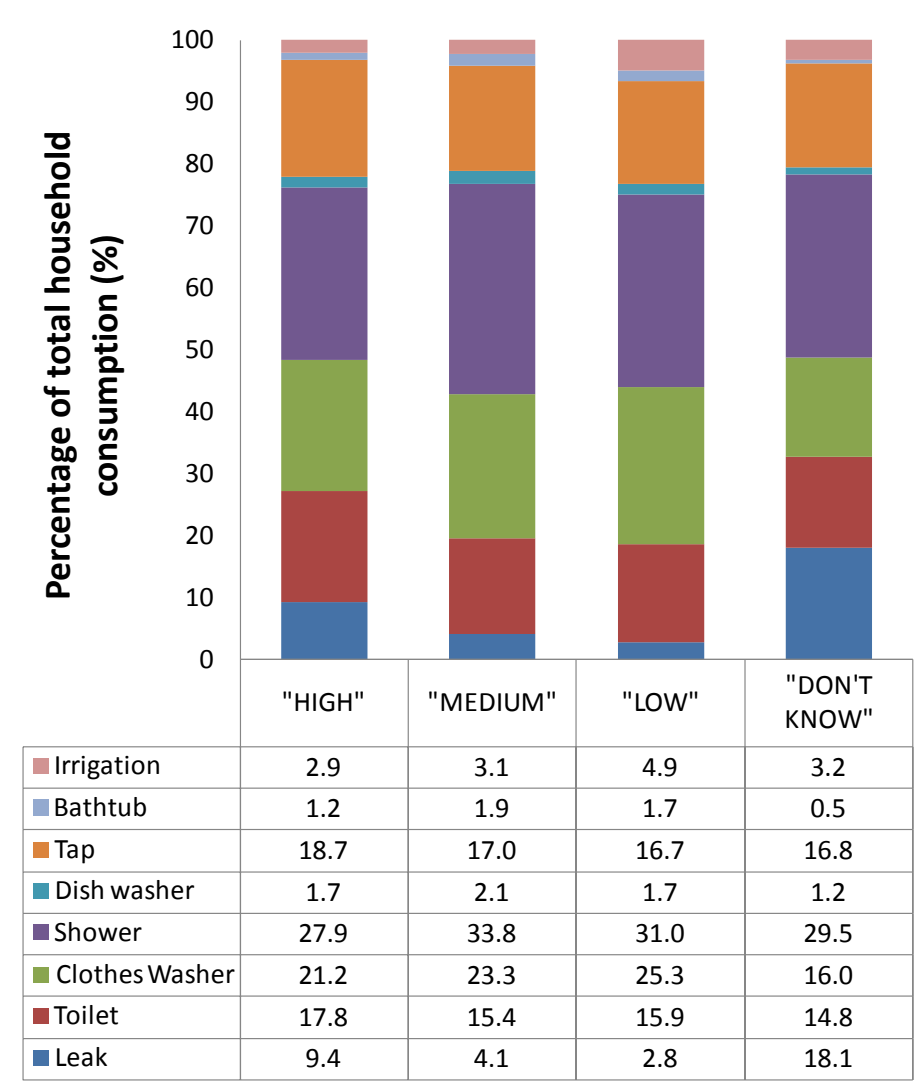

(b) Percentage of total household consumption (\%)

Figure 5 Comparisons of actual household water use with self-identified water users

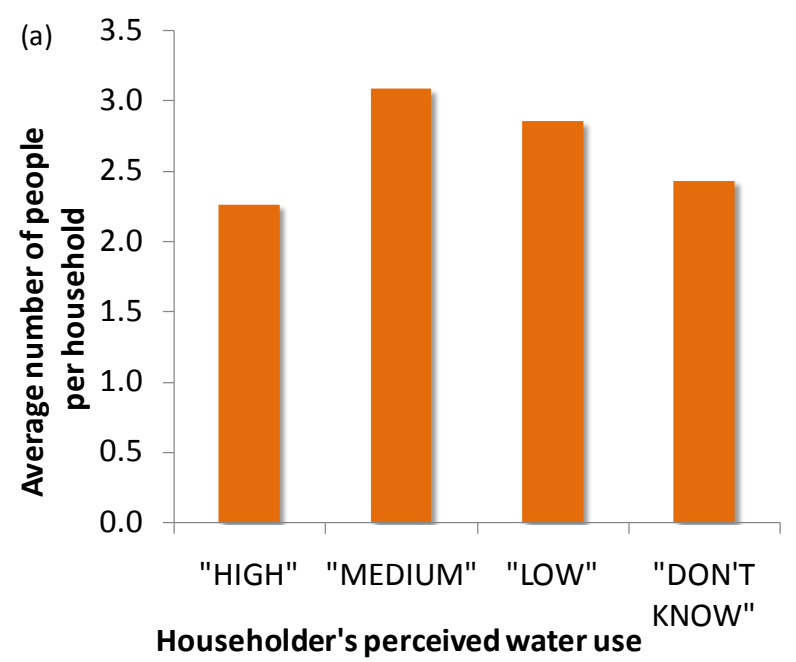




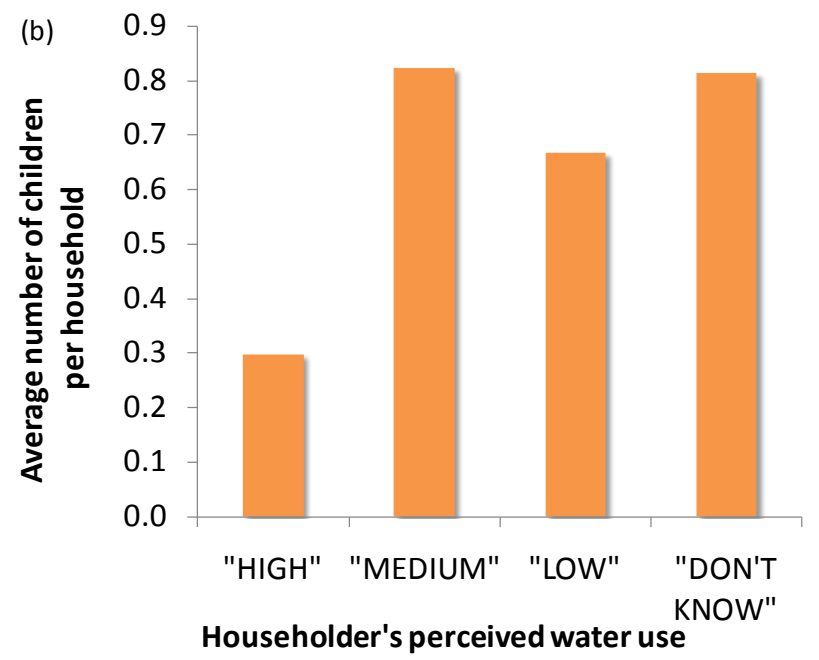

Figure 6 Selected family characteristics and self-identified water users

The 'high' water users fall in the lower household income category at an average income bracket of $\$ 50,000$ to $\$ 60,000$ (Figure 7). Based on data presented in Figures 3 and 6 , this group is more likely to be older householders with smaller families than higher income householders.

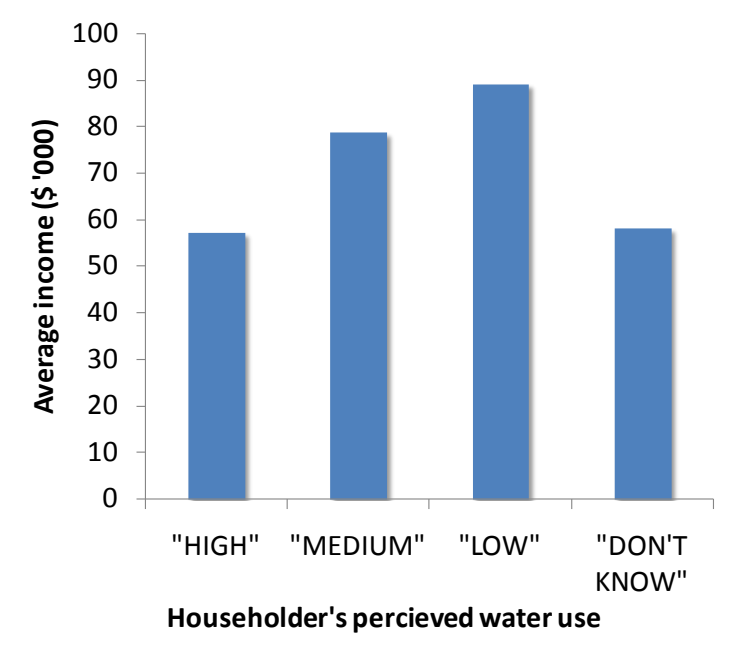

Figure 7 Comparisons of average incomes with self-identified users

In terms of water efficient appliances and fixtures there were some general trends for people who identified as low water users had higher star rated (Figure 8a) and water efficient (Figure 9a) clothes washers, and lower flow rated shower heads (Figure 9b).

Although not significant $(p>0.05)$ the group who identified as 'low' water consumers had a greater percentage of top loading washing machines (Figure 8b), and while historically they are associated with higher water use per washing loads, the current range of top loaders can have high water efficiency ratings, although they are typically more expensive. This may explain why the higher household incomes of the 'low' group have a higher rating water efficient washing machine than the selfreported 'medium' and 'high' groups. 

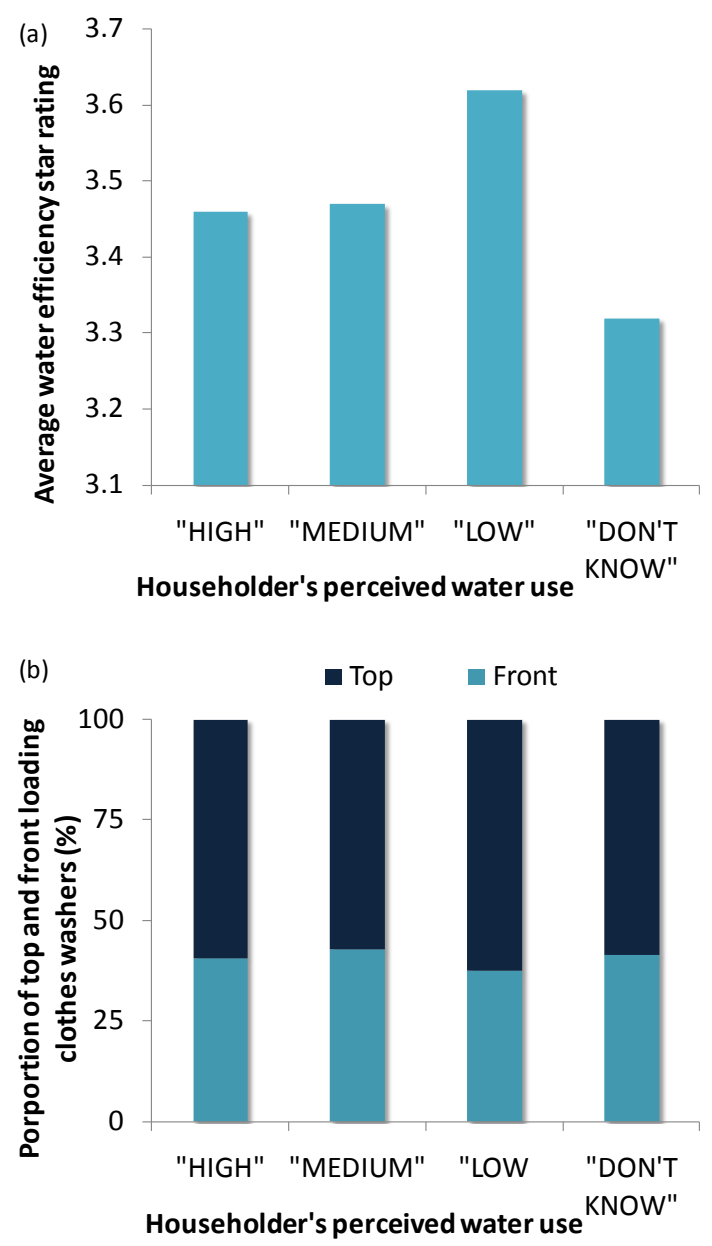

Figure 8 Comparisons of washing machine efficiencies and load types with self-identified water users

This data presented in this paper suggests that households who have high incomes and water efficient appliance/fixture stock generally perceive lower overall use of water. This may result in these households being less concerned about the behaviourally influenced end uses such as showering and taps, thereby pushing their overall consumption higher. Syme et al. (2000) noted that people with water efficient appliances are not necessarily effective in saving water elsewhere in the house. Following on from this, family size and composition, rather than the technology, may be the greater factor in determining household water demand. That is; you can have good technology but also need to match this with water conserving behaviour for non-automated water fixtures (e.g. shower and taps). Russell and Fielding (2010) observe that household size may inhibit water conservation practices due to a range of factors including limited financial or physical capacity and increased difficulty in establishing norms in a larger group of people. 

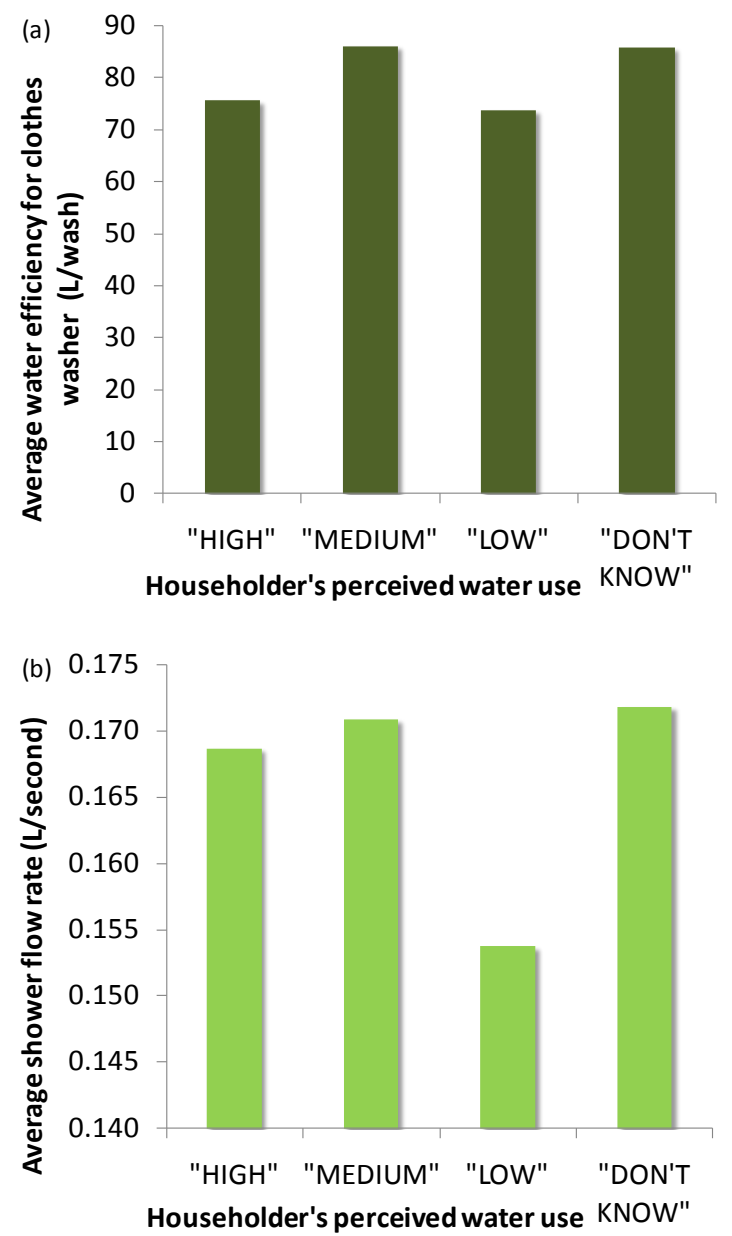

Figure 9 Comparisons of washing machine and shower fixture water efficiencies with selfidentified water users

The lack of feedback or education and awareness of how water is being used in the house may also be a factor in the water use perception not matching the water use behaviour. Hamilton (1985) also suggested that knowing one's water consumption would not only improve their self reporting but improve their conservation practices. Community Based Social Marketing can be such a means for achieving this (Kennedy 2010).

\section{CONCLUSIONS}

Knowledge on actual water consumption has been identified as an important factor influencing water consumption behaviour. In this regard, the current intervention study that is being conducted by an associated research team with the CSIRO will be examining the impact that interventions have on water use over time. One intervention is the provision of an end use pie chart (such as shown in Figure 2) to a sub sample of participants. This feedback on their water use may alter their initial perceptions on their household water use.

The general disparity observed between perceived and actual water use behaviour demonstrates that there cannot be exclusive reliance on individual household 
attitudes and beliefs to reduce water consumption. Mandatory measures such as water restrictions or incentives such as rainwater tank rebates are possibly more reliable in reducing residential demand. The general characteristics of the group people who overestimated their water use were: lower incomes; less children; small household occupancies; and are less likely to have water efficient technology. Conversely, the characteristics of the group who underestimated their water use were: higher incomes; larger families with young children; and tended to use more water efficient technology including low flow shower roses and higher star rated washing machines. A more detailed exploration of the discrepancy between actual and perceived water usage is currently underway using a larger dataset which will also consider psycho-social information.

\section{ACKNOWLEDGEMENTS}

This research was undertaken as part of the South East Queensland Urban Water Security Research Alliance, http://www.urbanwateralliance.org.au/.Particular thanks go to Allconnex Water, Urban Water Utilities, Unity Water, and the SEQREUS research team at Smart Water Research Centre.

\section{REFERENCES}

Beal, C., Stewart, R., Huang, T. and Rey, E. (2011) SEQ residential end use study. Australian Water Association Journal, 38(1), 80-84.

Fielding, KS., Louis, WR., Warren, C., Thompson. (2009) Environmental sustainability in residential housing: understanding attitudes and behaviour towards waster, water and energy consumption among Australian households. Australian Housing and Urban Research Institute Queensland Research Centre, AHURI Position Paper No. 121.

Hamilton, L. (1985) Self reported and actual savings in a water conservation campaign. Environment and Behavior 17(3), 315-326.

Kennedy, A. (2010). Using Community-Based Social Marketing Techniques to Enhance Environmental Regulation. Sustainability, 2(4), 1138-1160

Kenney, DS, Goemans, C, Klein, RA, Lowrey, J, Reidy, K (2008) Residential water demand management: lessons from Aurora, Colorado. Journal of the American Water resources Association, 44 (1):192-207.

Kim, S. H., Choi, S. H., Koo, J. K., Choi, S. I. \& Hyun, I. H. (2007) Trend analysis of domestic water consumption depending upon social, cultural, economic parameters. Water Science and Technology: Water Supply, Vol 7, No 5-6, pp. 61-68.

Millock, K., Nuages, C. (2010) Housheold adoption of water-efficient equipment: the role of socioeconomic factors, environmental attitudes and policy. Environmental Resource Economics, 46(2), 539-565.

Renwick, M. and Archibald, S. (1998) Demand side management policies for residential water use: who bears the conservation burden? Land Economics 74(3), 343-359. 
Russell, S., Fielding, K. (2010) Water demand management research: A psychological perspective, Water Resources Research, 46, W05302, doi10.1029/2009WR008408.

Spinks, A., Fielding, K., Russell, S., Mankad, A. and Price J. (2010) in Science Forum and Stakeholder Engagement: Building Linkages, Collaboration and Science Quality, (eds) D.K., Begbie and S.L., Wakem, Urban Water Security Research Alliance, September 2010, Brisbane, Queensland, pp 17.

Syme, G., Nancarrow, B. and Seligman, C. (2000) The evaluation of information campaigns to promote voluntary household water conservation. Evaluation Review 24(6), 539-578.

Turner, A., Fyfe, J., Retamal, M., White, S., Coates, A. (2009) The one to one water savings program unpacking residential high water usage. IWA Efficient 09 conference, Sydney, October 2009.

Willis, R., Stewart, RA., Talebpour, MR, Mousavinejad, A, Jones, S, Giurco, D. (2009) Revealing the impact of socio-demographic factors and efficient devices on end use water consumption: case of Gold Coast Australia. In Proceedings of the 5th IWA Specialist Conference 'Efficient 2009', Sydney, Australia

Wutich, A. (2009). Estimating household water use: a comparison of diary, prompted recall and free recall methods. Field Methods 21(1):49-6. 